\title{
Acquaintance and Fallible Non-Inferential Justification
}

Chris Tucker

College of William and Mary

Forthcoming in Michael Bergmann and Brett Coppenger (eds.). Traditional Epistemic Internalism. Oxford: Oxford University Press.

\section{Introduction}

Acquaintance is a kind of direct awareness. "When one is acquainted with a fact, the fact is there before consciousness. Nothing stands 'between' the self and the fact" (Fumerton 1995: 76). Classical foundationalists, whatever else they are, are rather prudish when it comes to non-inferential justification. Since acquaintance puts you in direct contact with reality, it is one of the few things that may satisfy their exacting standards. Let us say that (classical) acquaintance theory is any version of classical foundationalism that appeals to acquaintance in order to account for NIJ (noninferential justification). Richard Fumerton is arguably the leading proponent, but Evan Fales (1996), Ali Hasan (2013), and Michael Tooley (2013: 325-7), among others, also think of themselves as classical acquaintance theorists.

Acquaintance theories are well suited to account for a kind of infallible justification. Why am I justified in believing that I'm in pain? An initially attractive (partial) answer is that I'm acquainted with my pain. But since I can't be acquainted with what isn't there, acquaintance with my pain guarantees that I'm in pain.

What's less clear is whether acquaintance theories can account for fallible NIJ. In particular, it's unclear whether acquaintance theories leave room for misleading NIJ, NIJ to believe something false. I'll focus on introspective justification, but similar issues arise for a priori justification as well. It would be unfortunate if acquaintance theorists can't make room for misleading NIJ, for it is plausible that the following cases are possible:

- My sensation has exactly 8 speckles, but I have some non-inferential justification for thinking it has exactly 7 .

- The shade of red on the left side of my visual field is ever so slightly distinct from the shade of red on the right side; but I have some non-inferential justification for thinking that they are the same shade.

- My sensation is an itch that is ever so close to being pain but isn't, and I nonetheless have some degree of non-inferential justification for thinking that it's pain.

- The line in my visual field is curved ever so slightly, but I have some noninferential justification for thinking that it's straight. 
Fumerton and Hasan see the force of these examples and try to accommodate misleading NIJ from within classical acquaintance theory. I argue that these efforts fail. ${ }^{1}$

I focus on Fumerton's work. In section 2, I present Fumerton's account of noninferential justification. I argue that he can accommodate something like fallible NIJ for true thoughts. In the subsequent three sections, I assess whether he can accommodate fallible NIJ for false thoughts. In section 3, I show that Fumerton's account of fallible NIJ needs refinement and suggest how it can be refined. In secs 4 and 5, I argue that Fumerton cannot accommodate misleading NIJ. ${ }^{2}$ In section 6, I argue that Hasan cannot account for misleading NIJ while remaining a classical foundationalist.

\section{Fumerton's Account of Non-Inferential Justification}

Fumerton's account of non-inferential justification has two components, one concerning infallible justification and one concerning fallible justification. Fumerton has consistently endorsed the following account for infallible NIJ:

(INIJ) $\mathrm{S}$ has infallible non-inferential justification for $\mathrm{P}$ iff $\mathrm{S}$ is acquainted with the fact that $\mathrm{P}$, the thought that $\mathrm{P}$, and the (perfect) correspondence between the fact and thought.

If I have infallible NIJ that I'm in pain, it's because I'm acquainted with the fact that I'm in pain, the thought that I'm in pain, and the (perfect) correspondence between the thought and the fact.

At times, Fumerton has assumed that the infallible non-inferential justification is the only kind there is. ${ }^{3}$ At others, he endorses something like the following account of fallible NIJ:

(FNIJ) $\mathrm{S}$ has fallible non-inferential justification for $\mathrm{P}$ iff the fact that $\mathrm{P}^{*}$ is highly similar to the fact that $\mathrm{P}$, and $\mathrm{S}$ is acquainted with the fact that $\mathrm{P}^{*}$, the thought that $\mathrm{P}$, and a very high degree of correspondence between the fact that $\mathrm{P}^{*}$ and the thought that $\mathrm{P}^{4}$

For illustrative purposes, consider a marginal (painless) itch that is almost a pain. If I'm acquainted with the fact that the sensation is a painless itch, the thought that I'm in pain, and the near correspondence between the fact and the thought, then I have misleading NIJ that the sensation is pain. On the days when Fumerton allows for fallible noninferential justification, he's always thought that one has non-inferential justification iff one satisfies either INIJ or FNIJ.

\footnotetext{
${ }^{1}$ Fales (1996) also tries to accommodate misleading non-inferential justification from within classical foundationalism, but I don't have the space to address his views at length. I do, however, briefly discuss his views in note 15 .

${ }^{2}$ Poston (2010) argues that the possibility of misleading NIJ is in tension with what Fumerton says about the kind of assurance that justification is supposed to provide. I have sympathy with this criticism, but it shows only that Fumerton can't get everything he wants. I argue that Fumerton fails to make sense of misleading NIJ, regardless of what he ultimately decides concerning assurance.

${ }^{3}$ Poston (2010: 370-1) discusses some relevant passages, and Fumerton (2010: 379-80) acknowledges that he has been inconsistent in allowing for fallible justification.

${ }^{4}$ Sometimes in connection with fallible justification Fumerton additionally or instead requires that one's justification for $\mathrm{P}$ arise from a fact that $\mathrm{P}^{*}$, where that fact is easily or justifiably confused with the distinct fact that P. He stresses the "easily confused" language in his in his 2001: 75, but when he elaborates, how easily things are confused seems to boil down to how similar they are (75-6).
} 
I do think that Fumerton's acquaintance theory can accommodate one type of fallible NIJ. Contrast a searing pain with a marginal one. Fumerton holds that I have stronger justification that I'm in pain when the pain is searing than when it's very mild, and he claims that in the latter case my justification "is not very strong" (2010: 381). Nonetheless, "There is a sense, of course, in which my justification for believing that I am in pain is infallible when it consists, even in part, of my direct awareness of pain, however marginal that pain might be" (381, emphasis original). Here Fumerton wants to hold on to two ideas: my justification in the marginal pain case is weak but nonetheless includes my direct awareness of my pain.

FNIJ can accommodate both ideas. Since similarity is compatible with identity (identity's being the limit of similarity), let the fact that $\mathrm{P}^{*}$ and the fact that $\mathrm{P}$ both be that the sensation is pain. Assume that while Fumerton is acquainted with a high degree, $\mathrm{D}$, of correspondence between the fact that the sensation is pain and the thought that the sensation is pain, he's not acquainted with the perfect correspondence. FNIJ entails that he has fallible NIJ that the sensation is pain. Calling this justification "fallible" is inappropriate in one sense, because the sensation's being pain guarantees the truth of my thought. In another sense, however, it arguably counts as fallible justification. What made the pain satisfy FNIJ's conditions was not that it $i s$ pain but only that it's similar to pain. If a very similar painless itch also corresponds to the pain thought to degree D, then there's a sense in which he could've been mistaken.

Don't be distracted by whether this justification is best thought of as fallible or infallible (I don't really care one way or the other). Fumerton wants to allow that there is a lower grade of justification than the one identified by INIJ. I'm granting that he can account for a lower grade of non-inferential justification for true thoughts by allowing that one is acquainted with a high (but not perfect) degree of correspondence between the fact that $\mathrm{P}^{*}$ and the thought that $\mathrm{P}$. What I deny is that Fumerton's acquaintance theory can accommodate a grade of non-inferential justification for false thoughts.

\section{A Fixable Problem}

Recall Fumerton's account of fallible non-inferential justification:

(FNIJ) $\mathrm{S}$ has fallible justification for $\mathrm{P}$ iff the fact that $\mathrm{P} *$ is highly similar to the fact that $\mathrm{P}$, and $\mathrm{S}$ is acquainted with the fact that $\mathrm{P}^{*}$, the thought that $\mathrm{P}$, and a very high degree of correspondence between the fact that $\mathrm{P}^{*}$ and the thought that $\mathrm{P}$.

In the previous section, we focused on a case that plausibly involved fallible NIJ for a true thought. In this section, we focus on a case in which we might have fallible NIJ for a false thought. Consider again a marginal itch that is a very similar to pain without being a pain. Now suppose that:

A. I'm acquainted with the fact that my sensation is a painless itch, my thought that the sensation is a pain, and the very high degree of correspondence between the fact and the thought.

Since I've satisfied the conditions of FNIJ, Fumerton holds that A is sufficient for having (fallible) non-inferential justification that I'm in pain. Perhaps A can contribute to my having NIJ in some circumstances. What I argue in this section is that it's not sufficient: there are some circumstances in which A is true but I lack NIJ for thinking that I'm in pain. 
While the painless itch and the thought that this sensation is pain do correspond to a very high degree, the correspondence isn't perfect. Suppose that, in addition to A, it's also true that:

B. I'm acquainted with the fact that my painless itch fails to have perfect correspondence with my thought that the sensation is pain.

Does B's truth prevent A from providing me with NIJ to believe that the sensation is pain? I don't think so. At first glance, it may seem that to be acquainted with imperfect correspondence between a thought and a fact is to be acquainted with the thought's falsehood. But that's not quite right. Suppose I'm acquainted with the fact that my sensation has either 13 or 14 speckles, and I'm not acquainted with any fact that is more determinate. The thought that it has exactly 13 speckles will correspond to a high degree to the disjunctive fact. In such a case, I might be acquainted with the failure of perfect correspondence, but it doesn't follow that I'm acquainted with the thought's falsehood. We'll revisit imperfect correspondence in section 5. I'll argue that it isn't capable of supporting misleading NIJ, but the problem has nothing to do with the possibility of being acquainted with the failure of perfect correspondence.

Acquaintance with imperfect correspondence may not be a problem, but my sensation doesn't just imperfectly correspond to the thought that it's pain; it also perfectly corresponds to the thought that it's not pain. Consider the possibility that A is true and so is:

C. I'm acquainted with perfect correspondence between the fact that the sensation is a painless itch and the thought that the sensation is not pain.

Even if A can provide me with fallible NIJ in some circumstances, it's not obvious that it can provide me with fallible NIJ when $\mathrm{C}$ is also true.

We can make matters worse. Suppose that A is true and so is:

D. I'm acquainted with the fact that my sensation is a painless itch, my thought that the sensation is not pain, and the perfect correspondence between them.

According to INIJ, I have infallible NIJ that the sensation is not pain. When both A and $\mathrm{D}$ are true, Fumerton's account of non-inferential justification entails that I have (undefeated) fallible justification that the sensation is pain and (undefeated) infallible justification that the sensation is not pain. This result is counterintuitive, in part because it violates:

General Rule: it's impossible for one to have undefeated justification for believing $\mathrm{P}$ while also having undefeated justification for believing $\sim \mathrm{P}$.

While General Rule may have exceptions, alleged exceptions are guilty until proven innocent. Philosophers of language provide one way to argue that some exceptions are innocent. Assume Russellianism about proper names, i.e., assume that the meaning of a proper name just is its referent. On this view, the following two propositions are identical, because 'Mark Twain' and 'Samuel Clemens' have the same referent:

(MT) Mark Twain wrote Huckleberry Finn, and

(SC) Samuel Clemens wrote Huckleberry Finn.

Given the Russellianism about proper names, it doesn't seem crazy at all to think that one might have (undefeated) justification to believe MT and (undefeated) justification to believe $\sim \mathrm{SC}$. Yet, since MT and SC are the same proposition, we have a case in which it is possible to have undefeated justification to believe $\mathrm{P}$ but also undefeated justification to believe $\sim P$. 
Given Russellianism about proper names (or, more precisely, the analogous thesis concerning mental content), I think it's plausible that there is an important class of exceptions to General Rule. This Russellian strategy provides cases that intuitively seem to be exceptions to General Rule, and it provides a theoretical explanation of how the rule could be rationally violated, namely that a subject might reasonably fail to know that certain propositions are identical.

Fumerton, however, rejects Russellianism about proper names (2013, ch 5). On his view, 'If you really are using ' $a$ ' and ' $b$ ' as pure referring terms, then the statement 'a=b' will strike you as utterly trivial” (2013: 187). Since Mark Twain is identical to Samuel Clemens is not trivial, these proper names aren't pure referring terms. Perhaps Fumerton will argue that the cases I'm interested in-e.g., cases in which both A and D are true - are nonetheless legitimate exceptions to General Rule. If so, he needs to follow the example of the philosophers of language and find some way of motivating the idea that these cases really are exceptions.

Unless Fumerton can motivate an exception to General Rule, he needs to revise his account of fallible NIJ. What our discussion reveals is that satisfying the conditions identified by FNIJ isn't sufficient for NIJ. Satisfying those conditions doesn't provide NIJ for $\mathrm{P}$ when one also has infallible NIJ for $\sim \mathrm{P}$. This problem shows that FNIJ needs refinement, not that it needs to be abandoned. One simple fix is to add a no defeater condition to FNIJ. I'm fine with this fix, but I don't expect Fumerton to greet it with enthusiasm (e.g., 1985: 60-1; 2010: 385; personal correspondence). Whatever Fumerton ultimately decides, I'll assume that he can augment FNIJ in a way that addresses the problem raised in this section.

\section{Acquaintance with Contradicting Facts}

I now begin to criticize Fumerton's FNIJ in earnest. In this section, I argue that FNIJ must be understood in a way that respects a certain constraint. This constraint concerns which facts can contribute to non-inferential justification. In the next section, I argue that when the constraint is respected, FNIJ cannot account for misleading NIJ.

According to Fumerton, acquaintance with the truth-maker for a proposition is an essential component of any infallible justification for believing that proposition. Fumerton's account of fallible justification, however, does not require acquaintance with the truth-maker; it allows acquaintance with facts that aren't truth-makers to contribute to fallible NIJ. So far, so good. But Fumerton should not allow acquaintance with false-makers to contribute to one's justification for believing a proposition. Suppose I'm acquainted with the fact that my sensation is a painless itch. This fact is a false-maker for my thought that the sensation is a pain; therefore, it cannot contribute to any justification I have for thinking that the sensation is a pain. Let us say that a contradicting fact for $\mathrm{P}$ is any fact that non-trivially entails $\sim \mathrm{P} .{ }^{5}$ Perhaps there are more contradicting facts for $\mathrm{P}$ than there are false-makers for P. I tentatively think the worry generalizes to any contradicting fact. In other words, I propose:

\footnotetext{
5 "[O]ne fact entails another when the proposition the former makes true entails the proposition the latter makes true" (Fumerton 2010: 137, nt 3). A proposition A non-trivially entails another proposition B iff A entails B and the modal profile or conceptual content of both A and B contribute to the entailment. If B is necessarily true, then its modal profile guarantees, by itself, that every proposition entails it. But only some propositions will non-trivially entail B, e.g., the conjoined premises of an elegant proof.
} 
Constraint: If S's acquaintance with the fact that Q non-trivially entails the fact that $\sim \mathrm{P}$, then S's acquaintance with the fact that Q can't constitute, in whole or in part, any justification for $\mathrm{P}$ that $\mathrm{S}$ has.

I expect Constraint to sound plausible to most epistemologists. Indeed, Huemer (2007: 35) suggests something stronger, namely that acquaintance with such a fact might prevent me from having justification to believe that the sensation is a pain. While I think the stronger claim is plausible, weaker is safer. Constraint leaves open that I can be justified in believing that the sensation is pain even when I'm acquainted with the fact that it's a painless itch. What it denies is that my acquaintance with the sensation's being a painless itch can contribute to my justification for believing that it's a pain. Even some acquaintance theorists find such a weak constraint plausible. ${ }^{6}$

It's harder than you might expect to explain why Constraint is so plausible. Let us say that a justification for $\mathrm{P}$ is essentially errant or anti-infallible iff it guarantees (i.e. non-trivially entails) the falsehood of the proposition it justifies. It's popular (if not mandatory) to allow that we can be non-inferentially justified in believing necessary falsehoods. But it doesn't follow that a theory can properly allow $X$ to provide justification for $\mathrm{P}$ even though $\mathrm{X}$ guarantees that $\mathrm{P}$ is false. If Fumerton were to reject Constraint, then he would allow that we can have anti-infallible justification. He would allow that our justification for $\mathrm{P}$ can guarantee that $\mathrm{P}$ is false. Is this a problem?

It may seem obvious that anti-infallible justification is impossible, but we should tread carefully lest we rule out our own views. Suppose that a belief is justified if it is produced by a properly functioning faculty. Now suppose that, given an individual subject's evidence, a person's properly functioning inferential faculty produces the belief that there is no such thing as proper function. Our crude proper functionalism entails that the belief is justified. The existence of this justification guarantees that the belief is false, for the justification is provided by proper function and the belief denies that there is any such thing. Or suppose that process reliabilism is true, but that given the evidence at my disposal, my reliable inferential faculty produces the belief that the inferential processes human beings use aren't sufficiently reliable to be produce justified beliefs. Here again we have a case of anti-infallible justification: the reliability of my inferential faculty is at least part of what justifies my belief that no inferential process is reliable enough to produce justification. Here's one final example which hits closer to home. Suppose phenomenal conservatism is true and that I'm justified in believing that there is no such thing as a seeming, because it seems to me that there is no such thing as a seeming. If we rule out any sort of anti-infallible justification as impossible, then proper functionalists, reliabilists, and phenomenal conservatives should give up and go home, for they make anti-infallible justification possible in some circumstances.

If there is a problem with violating Constraint, it's not merely that Fumerton would allow for the possibility of anti-infallible justification. It's that he would allow for the possibility of a certain kind of anti-infallible justification. Let's look more carefully at the type of anti-infallible justification allowed by proper functionalists, reliabilists, and phenomenal conservatives. In each case, the anti-infallible justification results from a contradicting fact that is external to the subject's perspective. In each case, some unknown fact about the way the belief was produced (the belief was produced by proper

\footnotetext{
${ }^{6}$ Hasan vouches for its plausibility in section 6 of Hasan and Fumerton 2014.
} 
function, the process was reliable enough, the belief was caused by a seeming) entails that the believed proposition is false.

The cases of anti-infallible justification that seem especially problematic are due to contradicting facts that are internal to the subject's perspective. For example, suppose that Mary and Sherry are identical twins. Suppose I know them well enough to know that, on a given occasion, I'm talking to Mary. My knowledge that I'm talking to Mary can't provide justification for thinking that I'm talking to Sherry no matter how similar they may be. My knowledge puts a certain fact in my perspective - this person is Mary-which guarantees that the person is not Sherry. Consequently, my knowledge that the person is Mary can't justify me in believing that the person is Sherry.

The problem with violating Constraint is that it makes internal anti-infallible justification possible. To violate Constraint is to allow facts in my perspective that contradict P to contribute to P's justification. Suppose I'm acquainted with the fact that my sensation is a painless itch. If I'm acquainted with this fact, the fact is within my perspective. Indeed, you might think your being acquainted with a fact, having that fact directly before your consciousness, is the way to get a fact in your perspective par excellence. To allow acquaintance with this fact to justify my belief that the sensation is pain is to allow a fact within my perspective that contradicts $\mathrm{P}$ to justify $\mathrm{P}$.

I'll bet that you didn't find the kind of anti-infallible justification allowed by proper functionalism, reliablism, and phenomenal conservatism all that worrisome. And I bet that you find the sort of anti-infallible justification that would result from violating Constraint to be far more suspicious. My explanation is that when the contradicting fact is outside the subject's perspective, anti-infallible justification is no problem. When the contradictory fact is within the subject's perspective, as it is when one is acquainted with a contradicting fact, then it's a problem. I'm not entirely happy with this way of putting things, because even when I find "subject's perspective" talk illuminating, I also find it a bit vague and metaphorical. But this somewhat unhappy way of putting things is, I think, enough for us to latch on to what seems problematic about violating Constraint and why this problem does not generalize to rival epistemological theories. ${ }^{7}$

\section{Fallible NIJ without Contradicting Facts?}

If fallible non-inferential justification can't consist in acquaintance with contradicting facts, in what can it consist? How we word our answer will depend on how we understand the nature of sensations. Fumerton (2005: 127) rejects the idea that sensory states are intentional (representational). Instead, he seems to think that they are either sense data or ways of appearing (125, 127). Fumerton (133-4) sometimes assumes for convenience that sensory states are sense data. I will do likewise, because he "suspect[s] one can find ways of translating the relevant points into the language favored by the appearing theorist" (134). To say that a sensory state is a sense datum is to say that it is a special kind of object. "When someone hallucinates something red and

\footnotetext{
${ }^{7}$ If Russellianism about proper names is true, then we may have to tolerate some cases of internal antiinfallible justification. For example, a justified belief that (MT) Mark Twain wrote Huckleberry Finn might be used in an argument to establish that ( SC) Samuel Clemens did not write Huckleberry Finn, even though MT and SC are the same proposition. As I mentioned in the previous section, however, Fumerton rejects Russellianism about proper names.
} 
round, there may be no physical object present, but there is something present to consciousness and that thing really is phenomenally red and round" (125, emphasis original).

If sensory states are sense data, we need to distinguish between de re acquaintance and de facto acquaintance. De re acquaintance is acquaintance with an object and de facto acquaintance is acquaintance with a fact. De re acquaintance comes cheaply. Consider an analogy with de re seeing. If I see any truth about the squirrel, then I count as seeing the squirrel. If I see that it is moving, but I have no idea what kind of thing is moving, then I count as seeing the squirrel. Likewise, I'm acquainted with a sensation if I'm acquainted with any fact about it. I'm acquainted with a 48-speckled sensation if I'm acquainted with the fact that the sensation has many speckles or the fact that it has at least one. De facto acquaintance does not come so cheaply. Just as I can see the squirrel without seeing that it's a squirrel, I can be acquainted with a 48-speckled sensation without being acquainted with the fact that it has 48 speckles (cf. 2005: 1335). I might be acquainted with a painless itch without being acquainted with the fact that it's a painless itch.

For Fumerton, it is acquaintance with facts, not objects, that contributes to noninferential justification. For fallible NIJ, Fumerton's idea is that acquaintance with certain facts about painless itches can give rise to non-inferential justification that the sensation is a pain. Yet if I'm acquainted with some fact about the painless itch, then I'm acquainted with the painless itch and am, thereby, acquainted with something that guarantees that my thought is false. Is this a problem for Fumerton? I doubt it. If I merely see a squirrel (and do not see that it is a squirrel), this seeing does nothing to prevent me from being justified in believing that the object is a chipmunk. If I merely am acquainted with a painless itch (and am not acquainted with the fact that it is a painless itch), this acquaintance does nothing to prevent me from being justified in believing that the object is a pain. In the parlance from the previous section, your being acquainted with a painless itch isn't enough to put in your perspective the fact that it is a painless itch.

So which facts about the painless itch can contribute to non-inferential justification that the sensation is pain? According to Constraint, it can't be the fact that it is a painless itch. Here are some possibilities:

- the sensation's being pain-like, where being pain-like is compatible with being pain

- the sensation's having features that are (objectively) similar to those of borderline pains, where objective similarity is compatible with identity

- the sensation's sharing features with pains

- the sensation's having features $\mathrm{X}, \mathrm{Y}$, and $\mathrm{Z}$, where $\mathrm{X}, \mathrm{Y}$, and $\mathrm{Z}$ are features that pains also have.

In each of the first three possibilities, the relevant fact involves some comparison with pains. In the fourth possibility, the fact is just the sensation having certain features, where potentially unbeknownst to the subject those features are also had by pains.

To have fallible NIJ for the thought that I'm in pain, Fumerton requires that I have acquaintance with a fact that is "very similar" to the fact that I'm in pain. Each of these possibilities can make at least some sense of this idea. A sensation's being pain-like (at least when the pain-likeness is very strong) is presumably very similar to a sensation's 
being pain. A sensation's having $X, Y, Z$ when these features are prototypical of pain might count as being very similar to a sensation's being pain. Hence, we have a way of interpreting Fumerton that respects both Constraint and what little Fumerton says about fallible NIJ. In what follows, I don't distinguish between the four possibilities. They all suffer from the same basic problem.

Fumerton's account of fallible NIJ, as we are currently interpreting it, holds that awareness of a sensation's similarity to pain gets us NIJ for thinking we are in pain, at least when we are also acquainted with the thought that the sensation is a pain and the near correspondence between the fact and thought. Yet awareness of X's similarity to things of type $\mathrm{T}$ provides justification for thinking $\mathrm{X}$ is $\mathrm{T}$ only if one has some antecedent justification for believing that X's having these similarities reliably indicates being of type T. ${ }^{8}$ Perhaps a sensation's having certain similarities with pains guarantees that the sensation is a pain, and one can know that this guarantee obtains a priori. But we are considering whether Fumerton can account for misleading noninferential justification. For that purpose, we need to consider the kinds of similarities to pain that even painless itches can have. For such similarities, it is contingent whether having those similarities to pain reliably indicates being a pain. Hence, if my sensation's similarity to pain provides me with justification to believe it's pain, then I must have some antecedent empirical (e.g., perceptual or introspective ${ }^{9}$ ) justification for thinking that those similarities reliably indicate being pain.

Consider some analogies. My dusty minivan shares many similarities with my friend's minivan, but my minivan is a Toyota and his is a Honda. On the other hand, my minivan doesn't have much in common with the futuristically sleek and sporty FT1 , but the latter is also a Toyota. Professional cricket matches share many similarities with what takes place in Yankee stadium, but cricket is a lame sport and baseball isn't. On the other hand, what the kids in the street are doing bears little resemblance to what the Yankees are doing, but both activities arguably count as baseball. It takes empirical investigation to determine which similarities to things of type $\mathrm{T}$ reliably indicate being of type T. Likewise, it takes empirical investigation to determine whether X's sharing, say, certain phenomenal features with pain makes it likely that $\mathrm{X}$ is pain. And without some reason to think that these phenomenal features make it likely that $\mathrm{X}$ is pain, it's hard to see why awareness of these features would provide us with justification for thinking that $\mathrm{X}$ is pain.

I've argued in this section that, without some empirical justification for thinking that the similarities I'm aware of make it likely that the sensation is pain, then awareness of those similarities can't justify me in thinking that the sensation is pain. But suppose that I am antecedently justified in believing that those similarities make it likely that the sensation is in pain. For example, consider the following case:

E. (i) A sensation's having phenomenal feature F is similar to the sensation's being pain, (ii) I am antecedently and empirically justified in believing that

\footnotetext{
${ }^{8}$ A coherentist or holist can sensibly reject my claim that one needs this justification antecedently. It's a feature of their view that justification can emerge from certain collections of beliefs even if none those beliefs are justified antecedently to any other. Fumerton, though, doesn't seem to have much sympathy with such positions (e.g., see his 1995, ch 5)

${ }^{9}$ For simplicity, I'll also treat memorial and testimonial justification as empirical when they don't concern propositions for which we can have a priori justification.
} 
things which instantiate $\mathrm{F}$ tend to be pains, and (iii) I am acquainted with the fact that my sensation has $\mathrm{F}$, the thought that my sensation is pain, and the very high degree of correspondence between the thought and fact.

Perhaps E does provide me with justification for thinking that the sensation is pain, even if it is a painless itch. This would amount to misleading justification, but it's at least partly inferential. I never doubted that Fumerton could make sense of misleading justification when that justification is partly inferential. The issue in the paper is whether Fumerton can account for misleading non-inferential justification.

Consider E(ii). Given Fumerton's view, how could I have such justification? Perhaps I've noticed over time that these similarities are more often exemplified by pains than non-pains. In other words, perhaps I have some memorial justification that these similarities reliably indicate pain. But, for Fumerton, memorial justification is a type of inferential justification. Any justification composed in part of inferential justification is at least partly inferential.

Can I have non-inferential justification of the relevant regularity? Given that the regularity holds contingently, it's doubtful that I can be acquainted with it. If I can't be acquainted with that regularity, then Fumerton holds that I can't have infallible NIJ for thinking it obtains. Independently of the concern I'm pressing in this section, it's also doubtful that Fumerton's account of fallible NIJ can account for this justification. To have fallible justification that this contingent regularity holds, I need to have acquaintance with a similar fact. But what fact is similar to this contingent regularity but nonetheless is something with which I can be acquainted? I haven't the slightest idea. It seems, then, that any empirical justification I have for thinking that $a$ sensation's having $F$ indicates being pain must be at least partly inferential. If so, then any justification $\mathrm{E}$ might provide for thinking that the sensation is pain is at least partly inferential. Acquaintance with similar facts might help account for some kind of misleading justification, but not misleading non-inferential justification.

\section{Fumerton's Friends to the Rescue?}

Fumerton tries to make room for misleading non-inferential justification within his classical acquaintance theory, but his efforts seem to be in vain. Yet Fumerton isn't the only classical acquaintance theorist who tries to make room for fallible non-inferential justification. In this section, I consider the views of Ali Hasan. I'll argue that his view cannot accommodate misleading non-inferential justification while remaining true to classical foundationalism.

\subsection{Hasan's Principle: The First Horn}

Hasan tries to make room for fallible introspective justification by appealing to:

Hasan's Principle (HP): "[(i)] If one is directly aware of x's seeming to be $\mathrm{G}^{10}$, and [(ii)] if x's seeming to be G renders it probable for one that it is $\mathrm{G}^{11}$ then

\footnotetext{
${ }^{10}$ I've omitted a parenthetical clause for simplicity's sake, but I'm also a bit puzzled by the clause. The clause allows inclinations to believe, in addition to seemings, to contribute to fallible justification, provided that you are acquainted with the inclination. I doubt, however, that inclinations are the sort of thing to which one can be acquainted. One can be directly aware of a feeling that one is inclined, but not the inclination itself. If this is right, then HP is more committed on the ontology of seemings than Hasan (130, nt 20) seems to think.
} 
[(iii)] one thereby has at least some defeasible justification for believing that $\mathrm{x}$ is G" (Hasan 2013: 130; cf. Hasan and Fumerton 2014, sec 6).

The first condition of HP requires acquaintance, but HP represents a big departure from Fumerton's acquaintance theory. For Fumerton, there is supposed to be a deep parallel between the infallible and fallible cases of justification. In the infallible cases, we are acquainted with the fact that the sensation is a pain. In misleading fallible justification, acquaintance with some fact about the marginal itch provides us with justification for believing that the sensation is pain. In both cases, what provides us with justification is, essentially, acquaintance with facts about some sensation and some degree of correspondence between those facts and the thought that the state is a pain. According to HP what gives us fallible justification isn't acquaintance with the fact that the sensation is pain (pain-like) and the (near) correspondence with the fact and thought: it's acquaintance with the seeming that the sensation is a pain. And, in principle, it can seem to one that $\mathrm{x}$ is a pain even if $\mathrm{x}$ is a pleasurable feeling of deep fulfillment.

I do think that HP can account for misleading justification. It holds, roughly, that one has justification that one is in pain when one is acquainted with a seeming and that seeming makes it probable for one that P. I might satisfy these conditions even if my seeming leads me astray. The question is whether HP can account for misleading noninferential justification without abandoning classical foundationalism.

HP faces a dilemma. It concerns condition (ii). Suppose that a given seeming makes it probable for one that $\mathrm{x}$ is a $\mathrm{G}$. Does this probability hold contingently or necessarily between its relata? If it's the former, then HP can't account for misleading non-inferential justification. If it's the latter, then HP abandons classical foundationalism.

Suppose that the relevant kind of probability is contingent. Let ' $\mathrm{XG}$ ' be the proposition that $\mathrm{x}$ is a $\mathrm{G}$ and ' $\mathrm{S}_{\mathrm{XG}}$ ' be the seeming that $\mathrm{x}$ is a $\mathrm{G}$. What could explain why $\mathrm{S}_{\mathrm{XG}}$ makes XG probable? Perhaps it's that I have some memorial justification concerning the track record of my seemings: I've noticed that when I have $\mathrm{S}_{\mathrm{XG}}, \mathrm{XG}$ is usually true. Yet classical acquaintance theorists tend to think that memorial justification is inferential justification. If memorial justification for some propositione.g., usually when I have $S_{X G}, X G$ is true-partly explains why the seeming makes $X G$ probable, then any justification provided by HP is at least partly inferential.

Hasan's favored account of the relevant probabilistic connection apparently boils down to XG's truth being the best explanation of why I have $\mathrm{S}_{\mathrm{XG}}$ :

It is plausible that the shape's seeming to me to be pink makes it probable for me that it is pink, for it is plausible that the best explanation available to me of the fact that some phenomenal property attended to seems to have some phenomenal character $F$ is that it does have character F. (2013: 131)

When I discuss the second horn in the next section, we'll consider what follows if it's a necessary truth that $\mathrm{XG}$ is best explained by $\mathrm{S}_{\mathrm{XG}}$. If it's a contingent matter whether $X G^{\prime}$ 's truth is the best explanation of $S_{X G}$ for one, then what makes it the best explanation of $\mathrm{S}_{\mathrm{XG}}$ ? The traditional view, I take it, is that one's background knowledge

${ }^{11}$ Hasan builds more into (ii) than its wording suggests. He requires that one must also "grasp" the relevant probability relation $(129,132)$. I don't think my complaints about HP turn on whether we need to grasp the relevant probability relation, but I don't have the space to defend this point. 
is what determines whether something is the best explanation of something else. If I've never even heard of quantum mechanics, then quantum states won't be the best explanation of anything for me. If, on the other hand, I have justified beliefs about quantum mechanics, then maybe quantum states can be the best explanation of some fact for me. Given this traditional picture, then, HP can account for justification one has to infer the best explanation. ${ }^{12}$ Yet it can't account for non-inferential justification.

\subsection{Hasan's Principle: The Second Horn}

Hasan's Principle holds that (i) if you're acquainted with $S_{X G}$ and (ii) $S_{X G}$ makes it probable for one that XG, then you have defeasible justification for XG. We saw that if the probability relation in (ii) is contingent, then HP cannot account for misleading noninferential justification. We should consider, then, what happens when we think of the relevant probability as one that holds necessarily between $S_{X G}$ and $X G$. When we do, we'll find that HP would abandon classical foundationalism.

One very permissive alternative to classical foundationalism is:

Phenomenal Conservatism (PC): if it seems to $S$ that $x$ is a $G$, then $S$ thereby has at least some defeasible justification for believing that $\mathrm{x}$ is a $\mathrm{G} .{ }^{13}$

You should endorse PC; it's what all the cool kids are doing these days. But that's a point for another day. For today, the point is this: while HP doesn't collapse into PC, it's too close to PC to be something that will be attractive from the point of view of classical foundationalism.

A major objection to PC is that seemings caused by wishful thinking can provide prima facie justification for their content (see, e.g., Markie 2005: 356-7; Siegel 2012). HP will also be subject to such examples, because as Hasan notices, seemings can "be influenced by background cognitive states" (131). In my 2014, I argued that if this sort of objection to $\mathrm{PC}$ raises a genuine problem for $\mathrm{PC}$, it raises an equal or bigger problem for all of its rivals...except for one (58-9). I conceded that a Fumerton-style acquaintance theory may avoid these problems, so I managed to say something nice about Fumerton's view on that particular afternoon. But if Fumerton follows Hasan in endorsing PC, I'd have to take back that one nice thing I said about Fumerton's view.

PC and HP both allow wishfully produced seemings to justify their contents, but perhaps there are other differences between them that make HP more palatable to the classical foundationalist. One difference is that HP concerns only those seemings that make it probable for one that $\mathrm{x}$ is a $\mathrm{G}$. When the relevant kind of probability is contingent, this is a significant constraint. Some seemings to which PC grants justificatory power will be denied such power by HP. We are considering the possibility, however, that the relevant sort of probability holds necessarily. If it does

\footnotetext{
${ }^{12}$ Since part of the "inference base" is a non-doxastic state, a seeming, I follow Hasan in using "infers" and its cognates loosely (Hasan 2013: 132, nt 27). They key point is that the justification that emerges isn't purely non-inferential. It's not purely non-inferential justification because, in addition to the seeming that $\mathrm{X}$ is a $\mathrm{G}$, one needs antecedent justification for thinking that $\mathrm{X}$ 's being $\mathrm{G}$ is the best (and presumably also good) explanation of why it seems that $\mathrm{X}$ is G. This antecedent justification will presumably be empirical since, at this point, we are assuming that the relevant probability relation holds contingently.

${ }^{13}$ I articulate Phenomenal Conservatism this way to make it closer to the wording of HP. For defenses of phenomenal conservatism and more official articulations of the view, see Huemer (2007), Lycan (2013), and Tucker $(2010 ; 2011)$.
} 
hold necessarily, then the mention of probability in HP may not reflect substantive disagreement with PC. The proponent of PC may think there must be some sense in which seemings necessarily make their contents probable, otherwise why think that seemings necessarily justify their contents?

A second difference is that HP concerns only those seemings that one is acquainted with. If one can have seemings with which one is not acquainted, then only PC allows that such seemings have justificatory power. I'm not sure that there are any such seemings, but suppose that I can have a seeming that I'm not aware of. Speaking as one who defends PC, the seemings that I'm most confident that provide justification are the ones that I'm acquainted with; I don't have a settled opinion concerning the other ones. If it seems to me that $\mathrm{P}$, but I'm not in any way aware of this seeming, then perhaps that seeming can't justify. If so, then PC is false but might as well be true. Except for appeasing some controversial access requirement-e.g., E can justify $\mathrm{P}$ only if $\mathrm{S}$ is aware of E-there are no significant (dis)advantages to granting justificatory power to only those seemings with which one is acquainted.

There is supposed to be a third difference between HP and PC, namely that HP grants only introspective seemings the power to justify whereas PC grants such power to all seemings. This difference, if genuine, would make HP considerably more attractive to classical foundationalists; however, there is nothing in the wording of HP that would justify such a restriction. So why does HP apply only to introspective seemings? Hasan explains:

Can something similar to [HP] be used to defend the view that external world beliefs could be empirically foundational? Perhaps, but unless we can be directly aware of external world objects or their properties, something that classical foundationalists deny, the principle will have to specify some epistemically relevant relation between phenomenal or mental properties we can be directly aware of and non-mental properties of the external world, and this seems bound to introduce more complications and sources of error than in the case of introspection. (132)

For HP to grant perceptual seemings justificatory power, Hasan says we'd need direct awareness of either (a) some epistemically relevant relation between the mental seemings and the non-mental physical world or (b) physical objects and their properties. Since he's not optimistic that we can be acquainted with either one, he concludes that HP doesn't grant any perceptual seeming the power to justify.

Consider (a) first. It's simply false that we'd need to be acquainted with a connection between perceptual seemings and the physical world. At most what we'd need is acquaintance with a connection between perceptual seemings and their contents, contents which concern physical objects. Given our assumption in this sub-section that introspective seemings necessarily make their contents probable, why can't perceptual seemings necessarily make their contents probable? And if they necessarily make their contents probable, we presumably can be acquainted with that connection.

Now consider (b). Recall how HP applies to introspective justification. HP allows me to have justification that I'm in pain regardless of whether I'm acquainted with the fact that I'm in pain or some other mental state that is a lot like pain. This feature of HP 
is what makes HP such a big departure from Fumerton's work. ${ }^{14}$ What matters, for HP, is whether I'm acquainted with my seeming that I'm in pain. But I can be equally well acquainted with the way things seem, regardless of whether they concern what's going on in my own mind or what's going on around me. So why do I need to be acquainted with physical objects in order for HP to grant justificatory power to seemings?

Hasan will argue that we have a better explanation of a seeming when the seeming's content represents something we can be directly aware of. He contends that perceptual processing "seems bound to introduce more complications and sources of error than in the case of introspection" (132). Maybe, but it's still contingent whether introspective seemings are more reliable than perceptual ones. Indeed, it seems more important for our survival that we know when there's a tiger hunting us or when there's food available than that we can reliably distinguish 47 speckles in our visual field from 48 . We might expect, then, that some perceptual seemings are better explained by the truth of their contents than some introspective seemings. Despite these points, suppose that introspective seemings are always better explained by the truth of their contents than perceptual ones. If so, we'd have some explanation for why introspective seemings provide more justification than perceptual ones. It does not follow, however, that appeals to the best explanation are good enough to support justification in the introspective cases but not good enough in the perceptual cases. If Hasan justifies HP's truth by appealing to best explanation considerations, it's unclear to how many seemings HP grants justificatory power. Nonetheless, it apparently grants justificatory power to many perceptual ones.

My complaint about HP is not that it's false: it's that it can't account for misleading NIJ from within classical foundationalism. If HP's second condition requires the relevant probability relation to hold contingently, then HP can't account for misleading non-inferential justification. If the second condition instead requires the relevant probability relation to hold necessarily, HP has too much in common with phenomenal conservatism to be attractive from the point of view of classical foundationalism. Like phenomenal conservatism, it allows seemings produced by wishful thinking to have justificatory power. And, while it may not grant justificatory power to the full range of seemings as PC does, it grants justificatory power to many perceptual ones, which is a substantial departure from classical doctrine. ${ }^{15}$

\footnotetext{
${ }^{14}$ Hasan apparently fails to appreciate this departure when he appeals to Fumerton's account of fallible justification in note 29 (pg 132).

${ }^{15}$ Fales (1996) also tries to make room for fallible non-inferential justification. The probabilistic nature of such justification, he says, "is itself an element of the experience that grounds the judgment" (175). One way of understanding this view treats Fales as relying on a view like phenomenal conservatism. When Huemer talks about how we have justification for believing we are in pain when we are in pain, he allows that the seeming that one is in pain may be token identical to the pain, i.e. the pain can be a seeming of itself that it is a pain (2007: 46). Perhaps Fales takes Huemer's view one step further: painless itches can also be token identical to the seeming that one is in pain. Fales encourages this reading when talking about degrees of a priori justification. There he approvingly cites Bealer's (1992) account of intuition (Fales 1996: 185, nt 28; note referenced on pg 161). For Bealer (1992: 101-4), intuition is just an intellectual seeming to be understood analogously to perceptual seemings. On this PClike reading of his view, Fales allows introspective and a priori seemings to justify their contents. But then, like Hasan, he must explain why perceptual seemings can't justify their contents, if his view is to be attractive from the point of view of classical foundationalism. I suspect that he doesn't intend his view to
} 


\section{Conclusion}

This paper has concerned those versions of classical foundationalism that understand non-inferential justification at least partly in terms of acquaintance. Such views are well-suited to account for infallible non-inferential justification. If my acquaintance with my pain provides me with justification that I'm in pain, then my justification can't lead me astray. Yet there are a number of cases in which it is plausible that we can have non-inferential justification that does lead us astray. We considered two attempts to account for misleading non-inferential justification by appealing to acquaintance. We paid especially close attention to the views of Fumerton, but we also considered what Hasan had to say. Neither was able to account for misleading non-inferential justification while remaining a classical foundationalist. ${ }^{16}$

\section{References}

Bealer, George. 1992. "The Incoherence of Empiricism." Proceedings of the Aristotelian Society, Supplementary Volumes 66: 99-138.

Fales, Evan. 1996. A Defense of the Given. Lanham: Rowman \& Littlefield Publishers, Inc.

Fumerton, Richard. 2013. Knowledge, Thought, and the Case for Dualism. New York: Cambridge University Press. . 2010. "Poston on Similarity and Acquaintance." Philosophical Studies 147: 37986.

2005. "Speckled Hens and Objects of Acquaintance." Philosophical Perspectives 19: 121-138.

. 2001. "Replies to Pollock and Plantinga." In DePaul, Michael (ed.). Resurrecting Old-Fashioned Foundationalism. Lanham: Rowman and Littlefield, 69-78.

1995. Metaepistemology and Skeptcism. Lanham: Rowman \& Littlefield Publishers, Inc.

. 1985. Metaphysical and Epistemological Problems of Perception. Lincoln: University of Nebraska Press.

Hasan, Ali. 2013. "Phenomenal Conservatism, Classical Foundationalism, and Internalist Justification.” Philosophical Studies 162: 119-141.

Hasan, Ali and Richard Fumerton. 2014.

Huemer, Michael. 2007. "Compassionate Phenomenal Conservatism." Philosophy and Phenomenological Research 74: 30-55.

Lycan, William. 2013. "Phenomenal Conservatism and the Principle of Credulity." In Tucker, Chris (ed.). Seemings and Justification: New Essays on Dogmatism and Phenomenal Conservatism. New York: Oxford University Press, 293-305.

Markie, Peter. 2005. "The Mystery of Perceptual Justification." Philosophical Studies 126: $347-73$.

\footnotetext{
be interpreted in a PC-like way. Yet if not, it's unclear how probabilistic justification that one is in pain can itself be "an element of" a painless itch.

${ }^{16}$ Thanks to Michael Bergmann, Richard Fumerton, Ali Hasan, Ted Poston, and the audience of the 2014 Orange Beach Epistemology Workshop for helpful comments.
} 
Poston, Ted. 2010. "Similarity and Acquaintance: A Dilemma." Philosophical Studies 147: $369-78$.

Siegel, Susanna. 2012. 2012. "Cognitive Penetrability and Perceptual Justification." Nous 46: 201-222.

Tooley, Michael. 2013. "Michael Huemer and the Principle of Phenomenal Conservatism." In Tucker, Chris (ed.). Seemings and Justification: New Essays on Dogmatism and Phenomenal Conservatism. New York: Oxford University Press, 306-27.

Tucker, Chris. 2014. "If Dogmatists Have a Problem with Cognitive Penetration, You Do Too." Dialectica 68: 35-62.

. 2011. "Phenomenal Conservatism and Evidentialism in Religious Epistemology." In VanArragon, Raymond and Kelly James Clark (eds.). Evidence and Religious Belief. Oxford University Press, pgs 52-73.

. 2010. "Why Open-Minded People Should Endorse Dogmatism." Philosophical Perspectives 24: 529-45. 